Research Article

\title{
Fingerprint pattern examination of right hand thumb in relation to Blood Group
} Jha $\mathrm{L}^{* 1}$, Das KD ${ }^{2}$, Ahamad Z ${ }^{3}$

\author{
Sam Higginbottom Institute of Agriculture, Technology \& Sciences \\ Allahabad, India \\ \& \\ Department of Forensic Medicine \\ Janaki Medical College
}

1Assistant Professor, Department of Forensic Medicine and Toxicology, Janaki Medical College
${ }^{2}$ Assistant Professor, Department of Community Medicine, Janaki Medical College
${ }^{3}$ Associate Professor, Department of Forensic Medicine and Toxicology, Janaki Medical College

\section{ABSTRACT}

Background and Objectives: The study of friction ridge patterns of fingertip is known as dermatoglyphics. Although human beings have been using fingerprints as a means of identification for a long time, in this study an effort has been made to study a fingerprint pattern examination of right hand thumb in relation to ABO Rh blood group, so that one can get an idea about the expected blood group from the study of fingerprint pattern and vice versa.

Material and Methods: A plain thumb print was taken by applying ink to the tip of right hand thumb and place in the thumb directly on paper with a gentle pressure and the rolled fingerprint was taken by rolling the thumb on paper from outward to inward in such a way as to obtain an impression of whole tip. The blood group was determined and recorded along with other details of the study subjects after taking inform consent. Data were entered in excel and analyzed.

Results: It was observed that percentage of Loops were highest in AB blood group (76.92\%) and $O$ blood group with (71.05\%) common in A and B blood group with 57.14\%. Also, percentage of Whorls in A blood group was highest (42.86\%) as compared to lowest in AB blood group (23.08\%), in blood group B and 0 the distribution of whorls pattern are $39.28 \%$ and $28.95 \%$ respectively. Similarly, percentage of Arch was least in B blood group (3.84\%).

Conclusion: This study showed that there is an association between ridges of fingertip and different blood group

Key Words: Fingerprint, Blood group, Rh - type, Dactylography

\section{INTRODUCTION}

Cummins coined the term dermatoglyphic (derma=skin + glyphs=curves) to the dermal ridge configurations on the digits, palm and sole. Most human skin is quite smooth and covered with hair follicles and oil glands [1]. The finger, palm and sole areas, however has no hair or oil glands but instead have sweat pores and friction ridges that take various 
forms and shapes. The function of the friction ridges is to increase grip and the sense of touch. The study of friction ridge patterns is known as dermatoglyphics [2].

Most of the peoples are right handed in this world so a reliable personal identification is critical in the subject of forensics as is faced with many situations like civil, criminal, commercial and latest in financial transaction frauds, where the question of identification becomes a matter of paramount importance. Although human beings have been using fingerprints as a means of identification for a long time but in this study I have made an effort to take step further to "study a fingerprint pattern examination of right hand thumb in relation to ABO Rh blood group", so that one can get an idea about the expected blood group from the study of fingerprint pattern and vice versa [3].

\section{MATERIAL AND METHODS}

Each subject was asked to wash their hands thoroughly with soap and water and dry them using a towel. The individual being fingerprinted were asked to stand in front of and at a forearm's length from the fingerprinting paper. The individual should stand to the right and rear of the person taking the fingerprints. He was then asked to press his right hand thumb on the stamp pad and then to the paper to transfer the fingerprint impression by following ways (a) a plain of print was taken by applying ink to the tip of right hand thumb and place in the thumb directly on paper with a gently pressure. (b) The rolled fingerprint was taken by rolling the thumb on paper from outward to inward in such a way as to obtain an impression of whole tip [4]. In this way, the plain fingerprints of right hand thumb were taken separately on the respective blocks on the same sheet of paper. Care was taken to avoid sliding of right hand thumb to prevent smudging of the print. After the fingerprints demographic details name, sex etc were acquired and the blood group were examined as described by Upadhyay-Dhungel et al (2013) [5].

The details of their blood group were noted from their genuine document. Each subject was assigned a serial number. The fingerprint patterns (loops, whorl and arches) were studied with the help of a magnifying lens and were identified as: Loops, Whorls and Arches based on the appearance of ridge lines according to Henry's system of classification. The distribution of dermatoglyphic fingerprint patterns in right hand thumb of individuals and its relationship with different $\mathrm{ABO}$ and Rh blood groups was evaluated and analyzed.

\section{RESULTS}

All the sample of right hand thumb fingerprints was collected and analyzed statistically and tabulated as follows :.

Table 1: Distribution of Fingerprint Pattern ( $\mathrm{N}=$ 100)

\begin{tabular}{|c|c|c|}
\hline $\begin{array}{c}\text { Pattern of finger } \\
\text { print }\end{array}$ & No. of person & Percentage \\
\hline Loops & 65 & $65 \%$ \\
\hline Whorls & 34 & $34 \%$ \\
\hline Arches & 1 & $1 \%$ \\
\hline Total & $\mathbf{1 0 0}$ & $\mathbf{1 0 0 \%}$ \\
\hline
\end{tabular}

Table 1 shows that the distribution of fingerprints pattern of right hand thumb among 100 samples. The highest frequency is loop pattern with $65 \%$ and lowest frequency is Arch with 1\%, while the frequency of whorl is $34 \%$ only. 


\begin{tabular}{|c|c|c|c|c|c|c|c|c|c|}
\hline \multirow[t]{2}{*}{ Sex } & \multicolumn{8}{|c|}{ Blood group } & \multirow[t]{2}{*}{ Total } \\
\hline & $\mathrm{A}+\mathrm{Ve}$ & A-Ve & $\mathrm{B}+\mathrm{Ve}$ & B-Ve & $0+\mathrm{Ve}$ & O-Ve & $\begin{array}{l}\mathrm{AB} \\
\mathrm{Ve}\end{array}$ & AB- & \\
\hline Male $\%$ & $16 \%$ & $1 \%$ & $22 \%$ & $2 \%$ & $31 \%$ & $0 \%$ & $9 \%$ & - & $81 \%$ \\
\hline Female \% & $4 \%$ & - & $4 \%$ & & $5 \%$ & $2 \%$ & $4 \%$ & - & $19 \%$ \\
\hline Total count & $20 \%$ & $1 \%$ & $26 \%$ & $2 \%$ & $36 \%$ & $2 \%$ & $13 \%$ & - & $100 \%$ \\
\hline
\end{tabular}

Table 3: Distribution of various fingerprints pattern in $\mathrm{ABO}$ Blood groups $(\mathrm{N}=100)$

\begin{tabular}{|l|l|l|l|l|l|}
\hline $\begin{array}{l}\text { Fingerprints } \\
\text { Types }\end{array}$ & Blood gr. A & Blood gr. B & Blood gr. O & Blood gr. AB & $\begin{array}{l}\text { Total finger } \\
\text { tip typing }\end{array}$ \\
\hline Loops & $12(57.14 \%)$ & $16(57.14 \%)$ & $27(71.05 \%)$ & $10(76.92 \%)$ & 65 \\
\hline Whorls & $9(42.86 \%)$ & $11(39.28 \%)$ & $11(28.95 \%)$ & $3(23.08 \%)$ & 34 \\
\hline Arches & 0 & $1(3.57 \%)$ & 0 & 0 & 1 \\
\hline Total & $\mathbf{2 1}$ & $\mathbf{2 8}$ & $\mathbf{3 8}$ & $\mathbf{1 3}$ & $\mathbf{1 0 0}$ \\
\hline
\end{tabular}

Table 2 shows that maximum (38\%) of the study subjects belong to $\mathrm{O}$ blood group, whereas $\mathrm{AB}$ blood group contributes minimum $(13 \%)$ of the study subjects, $21 \%$ of subjects belong to A blood group and $28 \%$ of subjects belongs to B blood group.

Table 3 shows frequency and percentage wise distribution of various fingertip patterns in ABO blood groups. It was observed that percentage of Loops were highest in $\mathrm{AB}$ blood group (76.92\%) and 0 blood group with (71.05\%) common in A and B blood group with 57.14\%. Also, percentage of Whorls in A blood group was highest (42.86\%) as compared to lowest in $\mathrm{AB}$ blood group $(23.08 \%)$, in blood group $B$ and $O$ the distribution of whorls pattern are $39.28 \%$ and $28.95 \%$ respectively. Similarly, percentage of Arch was least in B blood group (3.84\%).

\section{DISCUSSION}

This study revealed that blood group $\mathrm{AB}$ and 0 had highest incidence of loops $(76.92 \%$ \& $71.05 \%$ respectively) followed by whorls (23.08\% \& $28.95 \%$ respectively), similarly in blood group A and B the loops pattern were common with $57.14 \%$ in both cases. It is different with the finding of the study in medical students of Nagpur, India where Meheta and Amit (2011) whorl were common in group ' $\mathrm{B}$ ', loops in blood group ' $\mathrm{O}$ ' and arches in group 'AB' [6]. The present study showed that the whorls pattern were highest in blood group A and B with (42.86\% $\& 39.82 \%$ respectively) while in blood group $\mathrm{O}$ and $\mathrm{AB}$ the frequency distribution of whorls were $28.95 \%$ and $23.08 \%$ respectively. Finally the frequency distribution of arch was $3.57 \%$ in blood group B. The general distribution pattern of the primary fingerprint was of the same order in 
individuals with $\mathrm{A}, \mathrm{B}, \mathrm{AB}$ and $\mathrm{O}$ blood groups i.e. high frequency of loops, moderate of whorls and low of arches as shown in table 3. This finding is similar with other findings [68]. This study shows that loops pattern were highest in blood group $A B$ and $O$, and common in blood group $A$ and $B$ in both cases. Similarly whorls were highest in A and $B$ blood group than $O$ and $A B$ blood group which is similar with other study [8] in which whorls were highest in $\mathrm{A}$ and $\mathrm{B}$ followed by $\mathrm{AB}$ and $\mathrm{O}$ [8]. So an association has also been found between distributions of Fingerprint pattern and blood groups.

\section{CONCLUSION}

The research work was based on fingerprint pattern examination of right hand thumb of 100 participants (81 male and 19 female) in relation to blood group. Study concluded that there is a strong correlation between blood groups and fingerprint pattern. From the study, it was concluded that the frequency distribution loops pattern were highest in blood group AB (76.92), $O$ (71.05\%) and B (57.14\%) respectively. Similarly, the study also concluded that the distribution of whorls were highest in blood group A with 42.86\% distribution, than in blood group $B$ with $39.28 \%$ distribution and for blood group $\mathrm{AB}$ it was found $23.08 \%$ and arches were least in blood group B with $3.70 \%$ distribution. Further study should be carried out by increasing the sample size to get more accurate representation of the population and need more similar studies in other regions too so that comparative study can be done.

\section{ACKNOWLEDGEMENT}

Authors are highly thankful to Sam Higginbottom Institute of Agriculture,
Technology \& Sciences, Allahabad, India to carry out this research.

\section{REFERENCES}

1. Cummins H. Palmar And Plantar (1926); Epidermal Ridge Configuration (Dermatoglyphics) in Europeans and Americans. Am J Phy Anthrop 1926; 179: 741802.

2. FSP. Fingerprinting teacher back ground information Australian school innovation science and technology, 2007.

3. Noor FI, Farida N, Irshad AH. Relation between fingerprints and different blood groups. Forensic 2012; 19(1):18-21

4. Reddy, KS. Text book of forensic medicine and toxicology twenty fourth ed. 2010.

5. Upadhyay-Dhungel K, Banskota GN, Das PK, Sohal A. Distribution of ABO and Rh blood groups in Nepalese medical students. Janaki Med Coll J Med Sci 2013; 1 (2): 17-20.

6. Mehta A, Amit A. Palmar dermatoglyphis In ABO, RH Blood groups. Int J Biol Med Res 2011; 2(4): 961 - 964.

7. Rastogi, Prateek, Pillai, Keerthi R. A study of fingerprints in relation to gender and blood groups. J Ind Acad Forensic Med 2010; 32(1).

8. Bharadwaja A. Saraswat PK, Agrawal SK, Banerji $\mathrm{P}$ and Bharadwaj S. Pattern of Fingerprints in different ABO blood groups. J Forensic Med Tox 2004; 21(2):49-52.

\section{Correspondence to:}

Lalan Jha

Assistant Professor

Department of Forensic Medicine

Janaki Medical College, Janakpur 